\title{
Tinjauan Yuridis Penguatan Eksistensi Usaha Lokal terhadap Toko Modern di Kabupaten Ponorogo
}

\author{
Muhammad Achwan ${ }^{1}$, Suyani $^{2}$ \\ ${ }^{\text {I}}$ Fakultas Hukum, Universitas Merdeka Ponorogo, Jl. Pacar 30, Ponorogo, 63418 \\ E-mail: mchwan44@gmail.com \\ ${ }^{I}$ Fakultas Hukum, Universitas Merdeka Ponorogo, Jl. Pacar 30, Ponorogo, 63418 \\ E-mail: suyani556@gmail.com
}

\begin{abstract}
The development of a modern market that is increasing will increase the development of local businesses. Therefore we need a regulation to protect the existence of local businesses. The purpose of this study is to examine the influence of modern markets on the existence of local businesses (SMEs, MSMEs, cooperatives and traditional markets) and the creation of an agreement for the birth of the Ponorogo Regency (PERDA) that supports local businesses (SMEs, MSMEs, cooperatives and traditional markets). Ponorogo district. The research method used is a qualitative research method with descriptive and quantitative methods. Data collection techniques are done through interviews, documentation and observation. Sampling is done through purposive sampling techniques or deliberate sampling with the consideration of highly skilled informants or debates that are properly discussed. Data were analyzed using qualitative data analysis techniques with interactive models. Juridical review is carried out by analyzing current juridical products, their implementation in the field and alternative legal products going forward.
\end{abstract}

Keywords—: modern markets; juridical; local businesses.

\section{LATAR BELAKANG MASALAH}

UUD 1945 dalam pasal 33 ayat (1) menyatakan, "Perekonomian disusun sebagai usaha bersama berdasar atas asas kekeluargaan"; ayat (3) menyatakan, "Perekonomian nasional diselenggarakan berdasar atas azas demokrasi ekonomi dengan prinsip kebersamaan, efisiensi berkeadilan, berkelanjutan, berwawasan lingkungan, kemandirian, serta dengan menjaga keseimbangan kemajuan dan kesatuan ekonomi nasional"(Mochtar, 2011). Jika mengacu pada bunyi pasal tersebut diatas seharusnya Indonesia sudah lebih awal melakukan sistem ekonomi yang mendahulukan kepentingan pembangunan ekonomi kerakyatan dari tingkat terbawah.

Sistem ekonomi yang diterapkan sejak kemerdekaan hingga kini bersifat liberal- kapitalistik-pasar bebas, sekaligus dualistik. Terbentuklah suatu disparitas yang sangat menyolok antara 95 perse penduduk pribumi yang memang sedari awal hidup dalam kemiskinan, kebodohan, dan ketertinggalan dalam kemakmuran ekonomi. Sementara 5 persen lainnya yang non pribumi menguasai 95 persen kekayaan ekonomi nasional (Naim, 2011). Para pengusaha asing dengan pasar modernnya menggeser usaha lokal. Hal ini perlu mendapat perhatian dari pemerintah guna kelangsungan eksistensi usaha lokal (UKM, UMKM, koperasi dan pasar tradisional), dari ancaman kepunahan akibat kalah bersaing dengan pasar modern.

Kapasitas dan kemampuan apa yang bisa mendorong daya saing Indonesia sehingga tidak kalah dengan negara lain. Potensi ekonomi kabupaten Ponorogo adalah merupakan bagian dari denyut nadi perekonomian nasional yang perlu mendapatkan perhatian.Untuk dipandang perlunya sebuah regulasi (PERDA) yang pro pelaku usaha lokal (UKM, UMKM, koperasi dan pasar tradaisional). Selain sumber daya alam yang melimpah juga penghasil aneka produksi yang berasal dari berbagai industri kecil yang terhimpun dalam suatu UMKM dan tersebar diseluruh pelosok kabupaten Ponorogo.

Keberadaan pasar modern secara umum memiliki 2 dampak yang harus diperhatikan yaitu, untuk dampak positif pendirian toko modern di kabupaten Ponorogo dapat mendorong pertumbuhan sosial dan ekonomi daerah. Sedangkan dampak negatifnya adalah mengancam ketahanan toko/pasar tradisional dan usaha kecil sejenisnya serta dapat memicu kerawanan sosial (disharmonisasi) (Dakhoir, 2018).

Kendala yang masih dihadapi oleh UMKM di Indonesia pada umumnya dan di kabupaten Ponorogo pada khususnya, adalah (1) pemasaran, (2) modal atau pendanaan, (3) inovasi dan pemanfaatan teknologi informasi, (4) ketersediaan bahan baku, (5) peralatan produksi, (6) penyerapan dan pemberdayaan tenaga kerja, (7) rencana pengembangan usaha, dan (8) kesiapan menghadapi tantangan eksternal (Wuryandani dan Meilani, 2013)

Penelitian ini bertujuan untuk mendorong lahirnya sebuah PERDA yang pro UMKM di Kabupaten Ponorogo. Adanya koordinasi yang mumpuni, adanya regulasi yang jelas dan implementative yang mampu melindungi keberadaan usaha lokal serta membendung dominasi pasar modern ikut berkompetisi hingga ke pelosok-pelosok daerah. 


\section{METODE PENELITIAN}

\section{A. Pendekatan masalah}

Pendekatan yang digunakan dalam penelitian ini adalah perundang-undangan (statute approach). Pendekatan perundangundangan digunakan untuk mengkaji hukum normatif. Dalam penelitian ini yang dimaksud dengan perundang- undangan adalah pasal 33 ayat (1) dan ayat (3) UUD 1945. Oleh karenanya tahapan yang dilakukan adalah menginventarisasi peraturan perundang-undangan, mengategorikan untuk dapat dianalisis. Berdasarkan analisis terhadap perundang-undangan diperoleh prinsip-prinsip dan aturan hukum yang berkaitan dan sekaligus dapat menjawab permasalahan.

Sumber bahan hukum adalah segala bentuk perwujudan hukum yang dapat menghasilkan hukum atau dengan kata lain asal mula hukum (Muchsin, 2006). Menurut Kansil (2008) sumber hukum adalah segala sesuatu yang menimbulkan peraturan yang bila dilanggar mengakibatkan sanksi. Sedangkan menurut Cohen dan Olson (2007) sumber bahan hukum terdiri dari sumber bahan hukum primer dan sekunder. Berdasarkan arti sumber bahan hukum seperti yang dijelaskan tadi, maka penelitian ini menitikberatkan pada sumber bahan hukum primer yang mengikat, yaitu: 1). Kaidah dasar; Pembukaan UUD 1945; 2). Peraturan dasar: pasal-pasal dalam UUD 1945 sebelum dan sesudah diamandemen.

Disamping sumber hukum primer, penelitian ini juga menggunakan sumber hukum sekunder: yaitu bahan yang berasal dari buku-buku teks, kamus hukum, artikel/ majalah/ jurnal ilmiah dibidang hukum, hasil penelitian maupun makalah seminar yang berkaitan dengan permasalahan penelitian.

\section{B. Teknik pengumpulan data}

Teknik pengumpulan data sekunder dikumpulkan dengan metode studi pustaka terhadap buku teks, artikel/ majalah, koran. Kemudian diolah berdasarkan kerangka pemikiran yang logis dan selanjutnya dianalisisa untuk menjawab permasalahan penelitian. Setelah data sekunder dikumpulkan maka tahap berikutnya adalah mengolah dan menganalisis data untuk menjawab permasalahan dalam penelitian. Pengumpulan data primer dilakukan dengan kuisioner pada pembeli di pasar modern dan penjual di UMKM disekiar pasar modern. Penjual UMKM dibedakan dengan radius dengan pasar modern, dibedakan menjadi 2 yaitu radius $100 \mathrm{~m}$ dan diatas $100 \mathrm{~m}$. Pemilihan pasar modern dibedakan menjadi 3 kategori yaitu dalam kota, pinggir kota dan pedalaman. Analisa data dilakukan dengan analisis korelasi dan regresi untuk menentukan hubungan pasar modern dengan perkembangan usaha lokal serta faktor yang sangat berpengaruh pada perkembangan usaha lokal.

\section{Analisis yuridis}

Analisis bahan hukum merupakan kegiatan untuk membuat sistematika dari bahan-bahan hukum tertulis dan diperlukan untuk membuat klasifikasi terhadap bahan-bahan tertulis, sehingga pekerjaan analisis dan konstruksi dapat dilakukan dengan mudah. Kegiatan-kegiatan yang dilakukan dalam analisis data yaitu: memilih pasal-pasal yang sesuai dengan permasalahan dalam penelitian, dan membuat sistematikanya sehingga menghasilkan klasifikasi tertentu. Berdasarkan langkah-langkah seperti yang tercantum pada metode penelitian, maka dilakukan analisis data yaitu inventarisasi data sekunder dan kemudian dikategorisasikan. Hasil analisis kemudian digunakan untuk membuat kesimpulan

\section{III.HASIL PENELITIAN DAN PEMBAHASAN}

\section{A. Karekteristik toko modern di kabupaten Ponorogo}

Karakterisik toko modern di kabupaten Ponorogo terdapat 5 jenis minimarket yaitu alfamart, indomaret, indoswalayan, innimart, asdiramart. Masing masing minimarket memiliki karakteristik yang berbeda. Ijin indomaret dimiliki oleh PT Indomarco Prismatama, Alfamart dimiliki oleh PT Sumber Alfaria trijaya. Minimarket di Kabupaten Ponorogo merupakan sisem waralaba. Sistem ini merupakan sistem pemasaran barang dan jasa dimana sebuah perusahaan induk memberikan kepada individu untuk melakukan usaha tertentu melalui cara tertentu yang sudah disepakati. Minimarket yang ada di Kabupaten Ponorogo

Tabel 1. Distribusi minimarket

\begin{tabular}{|r|l|c|c|c|c|c|c|}
\hline & Kecamatan & Alfamart & Indomart & Indoswalayan & Innimart & Asdiramart & Total \\
\hline 1 & Ponorogo & 7 & 9 & 1 & 1 & & 18 \\
\hline 2 & Babadan & 1 & 3 & & & & 4 \\
\hline 3 & Siman & & & & & & 0 \\
\hline 4 & Jenangan & & & & & & 0 \\
\hline 5 & Kauman & & 1 & & & & 1 \\
\hline 6 & Jetis & & 1 & & & & 1 \\
\hline 7 & Sambit & & & & & & 1 \\
\hline 8 & Mlarak & & & & & & 0 \\
\hline 9 & Sawoo & & & & & & 0 \\
\hline 10 & Pulung & & & & & & 0 \\
\hline 11 & Sokoo & & & & & & \\
\hline 12 & Ngebel & & & & & & 0 \\
\hline 13 & Balong & 1 & 1 & & & \\
\hline
\end{tabular}


Website : http://yustisia.unmermadiun.ac.id/index.php/yustisia

\begin{tabular}{|l|l|l|l|l|l|l|l|}
\hline 14 & Slahung & 1 & & & & & 1 \\
\hline 15 & Badegan & & & & & & 0 \\
\hline 16 & Sampung & & & & & & 0 \\
\hline & & 10 & 15 & 1 & 1 & 1 & 28 \\
\hline
\end{tabular}

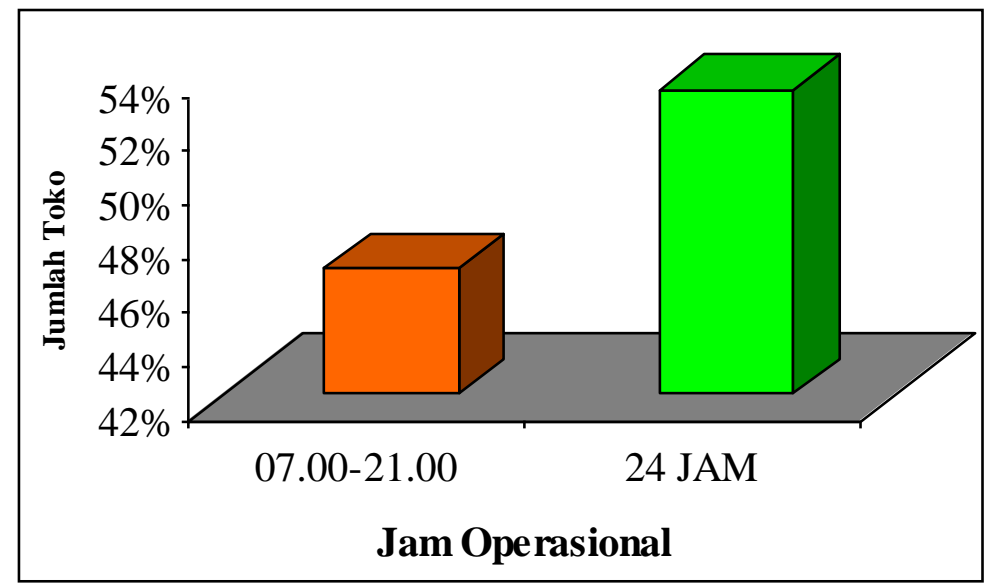

Gambar 1. Jam operasional toko modern

\section{B. Karakteristik toko usaha kecil di kecamatan Ponorogo}

Sistem kepemilikan usaha kecil ini memiliki karakteristik yang sangat unik, dimana kepemilikannya bersifat perseorangan baik dari isi permodalan maupun cara pengelolaan usaha ini. Masyarakat kabupaten Ponorogo sejak lama kebanyakan berprofesi sebagai pedagang selain bertani. Sebagian besarnya adalah kaum pedagang kecil, pengrajin makanan olahan serta berdagang dengan membuka toko kecil dirumah maupun dipasar tradisional. Meski pada perkembangannya usaha jenis ini nyaris tergusur oleh model pasar modern, namun para pelaku usaha kecil, UKM dan UMKM tetap bertahan untuk melanggengkan profesi yang diturunkan para generasi pendahulu secara turun-temurun.

Lama berdirinya toko usaha kecil di kecamaan Ponorogo didominasi oleh toko yang berdiri antara 6 - 10 tahun yaiu 32\%, kemudian diikuti oleh toko yang lebih dari 15 tahun. Hal ini menandakan bahwa perkembangan toko semakin meningkat (Gambar 2). Mengacu pada sistem pelayanan, jenis usaha kecil ini masih menggunakan model konvensional, yaitu pelayan adalah pemilik toko sendiri dan tanpa dibantu oleh karyawan. Hal ini disebabkan karena jenis usaha demikian masih relatif kecil dan mudah untuk dikendalikan, namun dampak lain dari model demikian adalah bahwa konsumen merasa tidak bisa leluasa untuk memilih barang maupun bila ingin menawar harga.

Kebanyakan usaha jenis seperti ini mulai buka antara pukul 06.00 hingga tutup pada pukul 20.00 WIB. Mengenai jam buka tutup ini sepenuhnya dikendalikan oleh pemilik usaha, yang karenanya terkadang tidak bisa permanen, atau sesuai keinginan pemilik toko. Waktu buka-tutup biasanya dipengaruhi oleh kepentingan jam istirahat, kesibukan khusus seperti kegiatan sosial, keagamaan, maupun acara keluarga. Setelah tercukupi kebutuhan ekonomi ataupun demi kepentingan sosial lainnya maka disitulah jam usaha ditiadakan alias kegiatan usaha tutup untuk sementara.

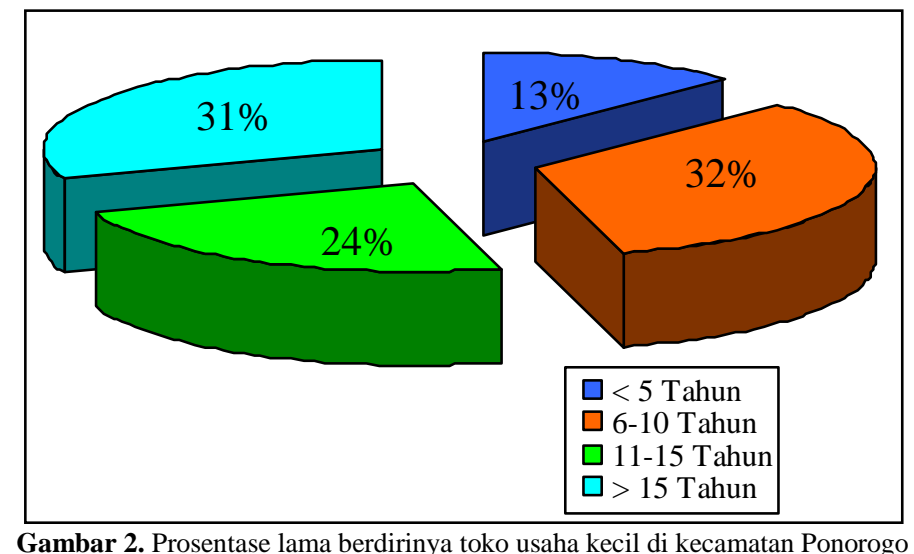

Toko yang berkembang disekitar minimarket merupakan toko yang banyak menjual bahan kebutuhan sehari hari. Toko kelontong memiliki persenase yang paling besar, kemudian diikuti toko sembako dan alat tulis. Toko yang paling sedikit adalah toko galon.Toko ini merupakan toko yang baru berkembang karena relatif baru (Gambar 3). Permodalan yang dimiliki oleh usaha jenis kecil ini biasanya relatif beragam dan biasanya tidak terlalu besar. Jika dibandingkan dengan jenis usaha modern 
semisal minimarket yang relatif hampir terstandardisasi dikarenakan terkait dengan aturan ijin usaha (SIUP), maka jenis usaha kecil ini memiliki sumber permodalan yang sangat terbatas, diantaranya adalah didapat dari tabungan pribadi, pinjaman keluarga, ataupun pinjaman lunak. Cara bisnis model ini cukup simpel, dimana pemilik usaha belanja (kulakan) barang kebutuhannya melalui toko grosir, agen, ataupun melalui supplier yang biasa keliling mendatangi para pemilik usaha kecil ini.

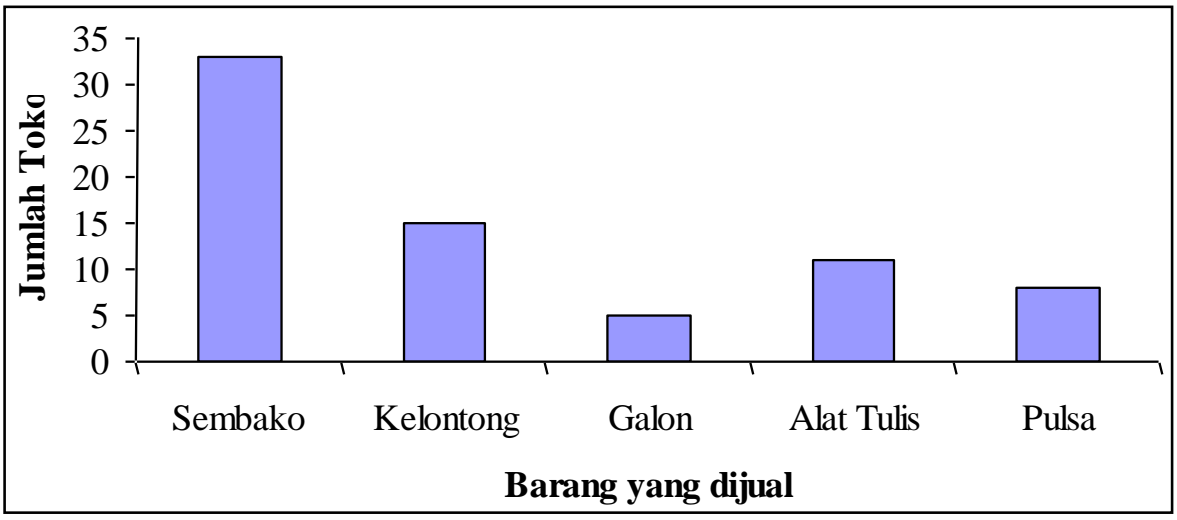

Gambar 3. Jumlah toko usaha kecil dengan jenis barang dagangan yang tersedia

\section{Persepsi dan preferensi masyarakat terhadap toko usaha kecil dan minimarket}

\section{Karakteristik konsumen}

Ditinjau dari tingkat pendidikan, pada umumnya para konsumen toko non modern dan toko modern didominasi oleh pendidikan SMA. Pada usaha jenis toko non modern banyak dikunjungi oleh mereka yang berpendidikan SMP sampai Perguruan tinggi, yang jumlahnya mencapai kisaran 28\% (Gambar 4), demikian pula pada jenis usaha toko modern banyak dikunjungi oleh mereka yang rata-rata berpendidikan SMA sampai perguruan tinggisebesar 32\% (Gambar 5).

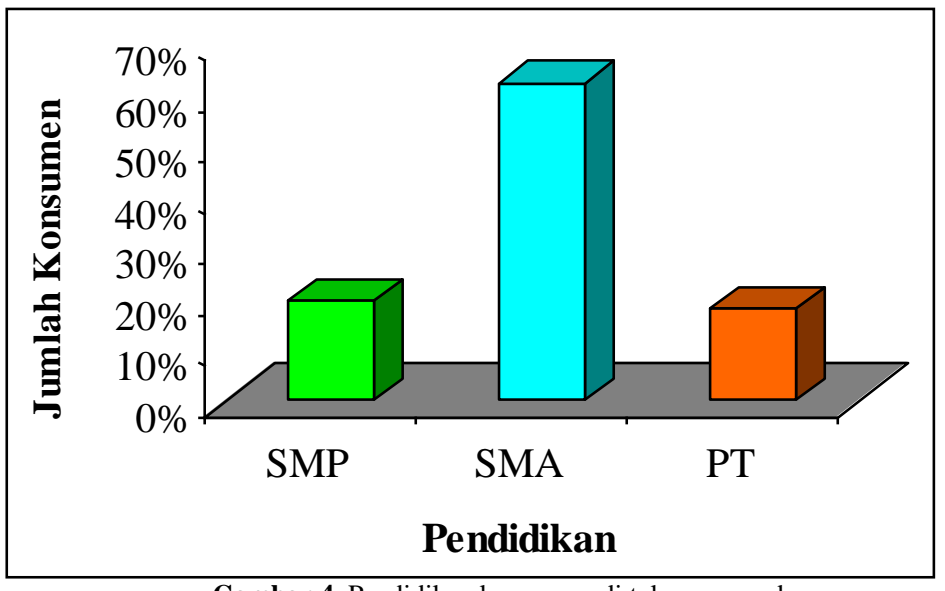

Gambar 4. Pendidikan konsumen di toko non modern

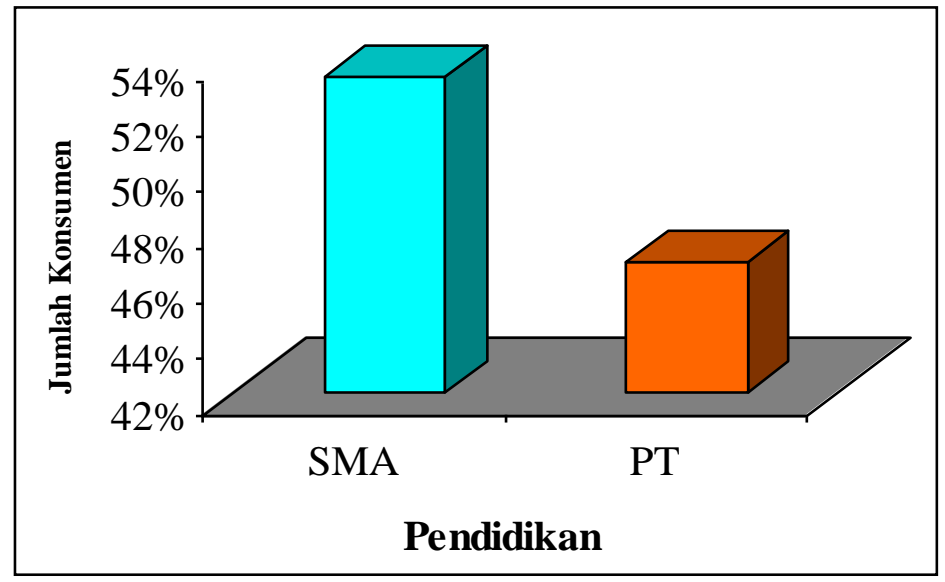

Gambar 5. Pendidikan konsumen di toko modern 


\section{Persepsi masyarakat pengunjung}

Berdasarkan persepsi pengunjung pada toko non modern maka kelebihan toko non modern adalah harga lebih murah yaitu terdapat 47 persen responden, kemudian diikuti oleh jumlah pembelian kecil sebesar 26\% (Gambar 6). Berdasarkan persepsi pengunjung toko modern maka toko modern memiliki kelebihan pada kebebasan memilih dan potongan harga yaitu 33\% dari jumlah pengunjung, kemudian diikuti oleh kelengkapan pada toko modern (13\%) (Gambar 7).

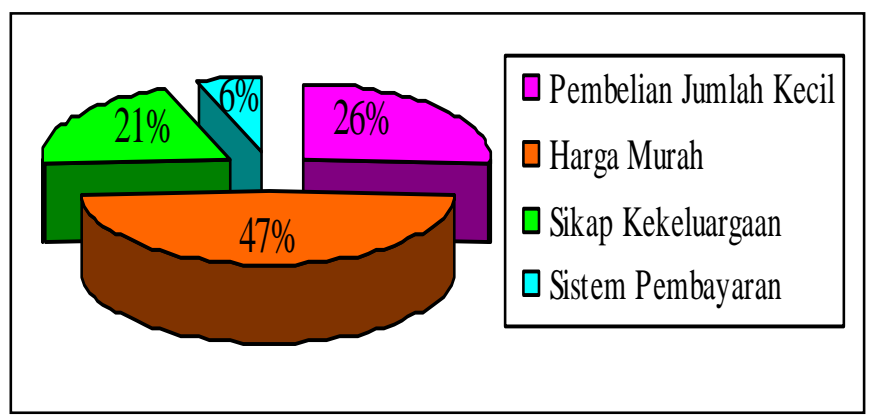

Gambar 6. Alasan Berbelanja di toko non modern

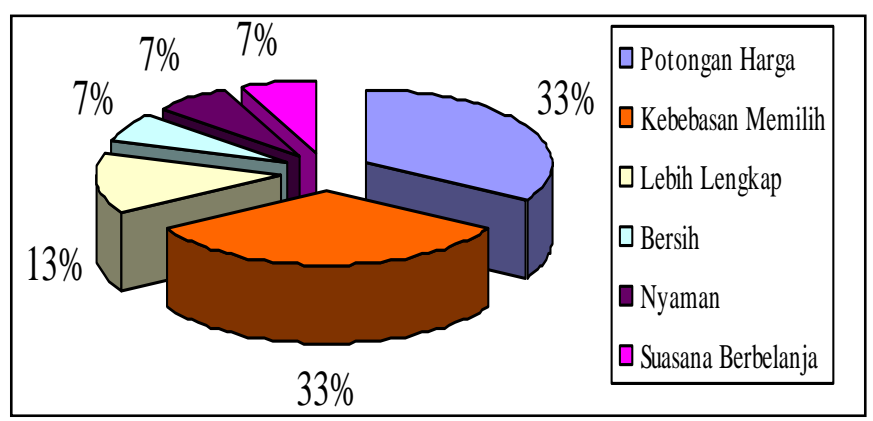

Gambar 7. Alasan Berbelanja di toko modern

Jarak toko non modern dengan toko modern menentukan pendapatan toko non modern. Toko modern dengan jarak kurang dari 100 meter akan mengakibatkan penurunan jumlah pendapatan dengan adanya kehadiran toko modern (Gambar 8), sedangkan untuk jarak lebih dari 100 meter tidak terpengaruh pada kehadiran toko modern (Gambar 9).

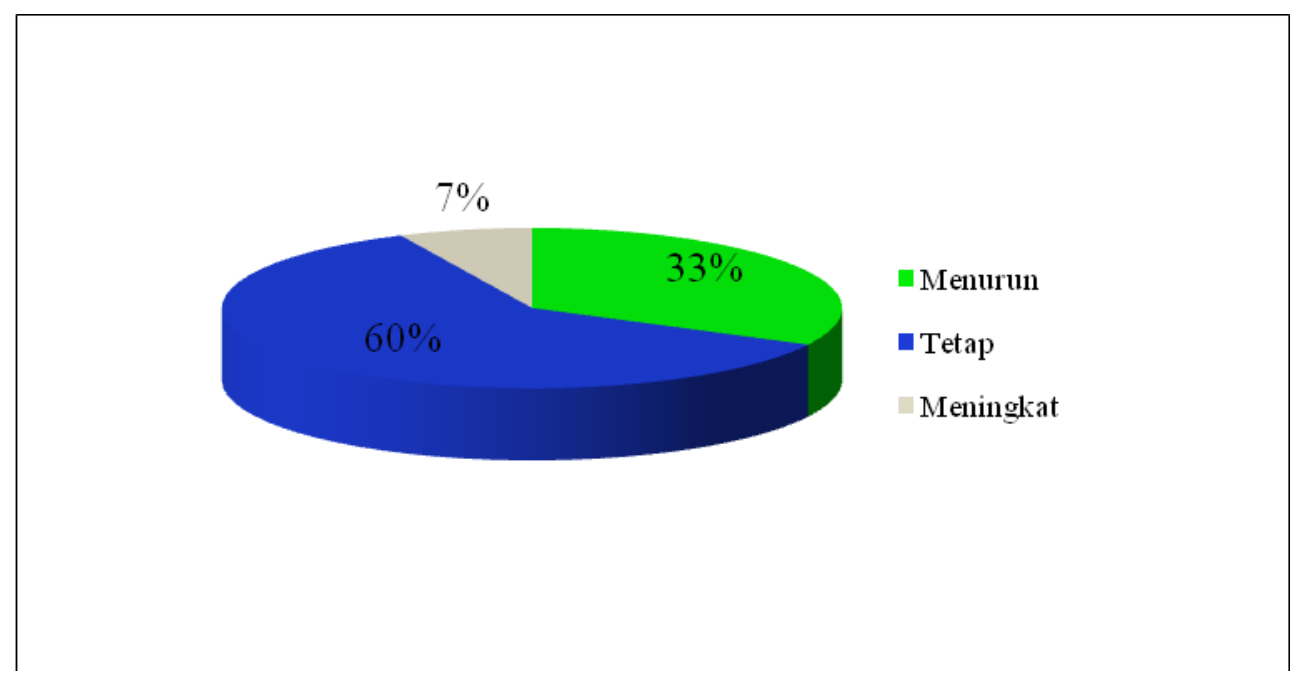

Gambar 8. Pendapatan toko non modern pada jarak lebih dari 100 dari toko modern 
Website : http://yustisia.unmermadiun.ac.id/index.php/yustisia

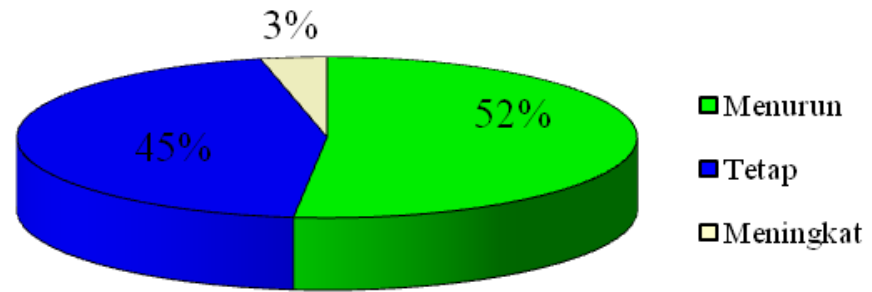

Gambar 9. Pendapatan toko non modern pada jarak kurang dari 100 dari toko modern

\section{Kajian hukum}

Peraturan Presiden Nomor 112 Tahun 2007. Peraturan Presiden yang mengatur tentang penataan dan pembinaan Pasar Tradisional dengan Pasar Modern merupakan aturan main bagi pelaku usaha dibidang perdagangan antara pasar tradisional dengan pasar Modern, adapun yang diatur dalam peraturan tersebut adalah: a. Batas luas lantai penjualan toko Modern Minimarket kurang dari $400 \mathrm{~m} 2$ ( empat ratus meter persegi) Supermarket $400 \mathrm{~m} 2$ (empat ratus meter persegi) sampai dengan $5.000 \mathrm{~m} 2$ ( lima ribu meter persegi). b. Pengaturan Lokasi pasar modern hanya boleh berlokasi pada akses system jaringan jalan atau kolektor primer dan sekunder, sementara pasar tradisional boleh berlokasi pada setiap system jaringan jalan. c. Perizinan d. Pembinaan pengawasan e. Pemberdayaan.

Pasal 3 ayat (9) Permendag nomor 53 tentang pedoman penataan dan pembinaan pasar Tradisional, Pusat Perbelanjaan dan Toko Modern/ Pasar Modern menyebutkan kewajiban bagi pasar modern yaitu pendiri pasar modern baik berdiri sendiri maupun yang terintegrasi dengan Pusat Perbelanjaan atau bangunan lainnya wajib memperhatikan: a. Kepadatan Penduduk b. Perkembangan Pemukiman Baru c. Aksesibilitas wilayah ( arus lalu lintas) d. Dukungan / Ketersediaan infrastruktur dan e. Keberadaan pasar tradisional dan warung/ toko diwilayah sekitas yang lebih kecil dari pada minimarket.

\section{IV.KESIMPULAN}

Keberadaan toko modern di Ponorogo berdampak negatif pada perkembangan toko non modern dalam radius kurang dari 100 $\mathrm{m}$, ditinjau dari penurunan pendapatan toko non modern, sedangkan radius lebih dari $100 \mathrm{~m}$ tidak terpengaruh dengan adanya toko modern. Demi eksistensi toko non modern perlu adanya suatu regulasi berupa peraturan daerah (PERDA) kabupaten Ponorogo untuk menjamin keberlangsungan usahanya dan agar masyarakat Ponorogo mampu menjadi pemain tuan rumah serta tidak menjadi tamu dikampung sendiri.

\section{DAFTAR PUSTAKA}

Dakhoir A, "Eksistensi Usaha Kecil Menengah dan Pasar Tradisional dalam Kebijakan Pengembangan Pasar Modern", Jurnal Studi Agama dan Masyarakat 14 ( 01), 2018.

Wuryandani D, Meilani H, "Peranan Kebijakan Pemerintah Daerah Dalam Pengembangan Usaha Mikro, Kecil, Dan Menengah Di Provinsi Daerah Istimewa Yogyakarta", Yayasan Akatiga, 2013.

Sarwoko, E, "Dampak Keberadaan Pasar Modern Terhadap Kinerja Pedagang Pasar Tradisional Di Wilayah Kabupaten Malang", Jurnal Ekonomi Modernisasi, 4(2), 2008.

Kupita W dan Bintoro RW, "Implementasi Kebijakan Zonasi Pasar Tradisional Dan Pasar Modern (Studi Di Kabupaten Purbalingga)", Jurnal dinamika hukum, Vol $12(1), 2012$.

Syukriah dan Hamdani I, "Peningkatan Eksistensi Umkm Melalui Comparative Advantage Dalam Rangka Menghadapi MEA 2015 Di Temanggung", Economics Development Analysis Journal 2 (2), 2013.

Munizu M, "Strategi Peningkatan Kinerja dan Peran Usaha Kecil dan Menengah (UKM) Pegolah Produk Berbasis Pangan di kota Makassar", Jurnal Ubaya, 2013.

Kurniawanysah D, "Penerapan Pencatatan Akuntansi Dan Penyusunan Laporan Keuangan Berdasarkan Sak Etap Pada Umkm Desa Gembongsari Kecamatan Kalipuro Kabupaten Banyuwangi", Dinamika Global : Rebranding Keunggulan Kompetitif Berbasis Kearifan Lokal , 2016. 